\title{
DSP based Pulse Generation for Induction Motor Speed Control
}

\author{
Hardik A.Shah \\ Research Scholar,Electrical \\ Engg.Deptt.,FTE \\ M.S.University of Baroda,India
}

\author{
Satish K.Shah \\ Electrical Engg.Deptt. \\ FTE \\ M.S.Unversity of Baroda, India
}

\author{
Viranchi C Pandya \\ E \& C. Department, \\ A.D.Patel Institute of Tech. \\ New V.V.Nagar, India
}

\begin{abstract}
This paper presents real time implementation of DSP based Sine PWM control algorithm for 3 phase 4-leg IGBT voltage source inverter. This method is useful to control the speed of Voltage source Inverter fed Induction motor drive. The pulses were generated using DSP controller through MATLAB Simulink - Code Composer Studio environment and that triggers the inverter. Results of input and output of the inverter were captured using Digital Storage Oscilloscope. Simulation study was carried out using PSpice and results verified.
\end{abstract}

\section{General Terms}

Signal processing ,Power electronics, A.C.drives control

\section{Keywords}

Digital Signal Processor (DSP), Induction Motor, Sine Pulse Width Modulation (SPWM), Voltage Source Inverter, PSpice

\section{INTRODUCTION}

Ac machines were introduced almost hundred years before even though research in this area is still continue because of the latest development of the power electronics semiconductor devices and power electronics converters and high performance controllers like DSP. The control of ac drives generally requires complex control algorithms that can be performed by microprocessors or high speed controllers along with fast switching power converters. AC machines require control of frequency, voltage and current for variable speed applications. The speed of ac machines depends on frequency of supply systems and it is fixed. Variable speed of the ac machines is required for many applications like electric propulsions, pumps, fans, compressors, actuators, spindles, servos etc. Induction machines, synchronous machines and variable reluctance machines are the main types of ac machines. The main components of the variable speed drive systems are electric machines, converters, controllers and load. Induction machines are most common and famous ac drives for variable speed applications due to disadvantages of dc machines such as higher cost, higher rotor inertia and commutation problems. Induction machines applications include pumps, fans, variable speed wind energy systems, variable speed constant frequency systems etc. converters used for variable speed drives system are controlled rectifier, inverters and cyclo converters. The applications of the converters include electrochemical processes, adjustable speed ac and dc motor drives, high voltage dc systems, dc and ac general purpose power supplies and $\mathrm{dc}$ to ac power conversions etc [1-3].Current source or current fed inverters likes stiff $\mathrm{dc}$ current source at the input. Voltage fed or voltage source inverter is more popular in industrial drive applications for induction motor speed control [1-3].Voltage fed converters converts fixed or variable dc voltage to ac voltage of constant magnitude and constant or variable frequency. The inverter output can be single phase or poly phase of square wave, sine wave, PWM wave, Stepped wave or quasi square wave. These converters are used mainly in UPS, AC drives and Induction heating applications. In machine drive applications the range of voltage \& frequency is wide. Inverter frequency control can be done by generating signals from microcontroller, hardware \& software counters, D/A converters etc. The inverter output voltage can be controlled by inverter input voltage control (Pulse Amplitude modulation) or by voltage control within the inverter (Pulse width modulation) [1-3, 11].PWM approach is based on switching control in the inverter to control the voltage and optimize the harmonics. PWM techniques are sinusoidal PWM (SPWM),Selected harmonics elimination (SHE)PWM ,minimum ripple current PWM, Space vector PWM (SVM), Random PWM, hysteresis band current control PWM, Sinusoidal PWM with instantaneous current control etc.PWM techniques classified on the basis of voltage or current control, feed forward or feedback methods, carrier or non carrier based control methods etc[1-3]. In [8] digital simulation of sinusoidal pulse width modulation presented, at rated frequency efficiency for induction motor drive was higher with sinusoidal pulse width modulation technique in comparison with sinusoidal supply. Sinusoidal pulse with modulation technique is very famous technique for voltage source inverter because it is simple in implementation with low output harmonic contents [1, 9-10]. Analysis of six switches based three phase inverter and four switches based three phase inverter with PWM and Sinusoidal PWM comparison shows unbalanced phase currents, speed variations and higher THD of four switch three phase inverter fed induction motor discussed in [14]. Speed control is achieved in inverter driven induction motor by means of variable frequency. This can be achieved by constant voltage $/ \mathrm{Hz}$ control, constant slip speed control, constant air gap flux control and vector control. Different control techniques of induction motor drives are scalar control, vector or field oriented control, direct torque and flux control, adaptive control and intelligent control with fuzzy logic, expert system and neural network [1]. This paper is organized as follows. Three phase Sinusoidal PWM based inverter fed induction motor drive is reviewed in Section II. Proposed system design is presented in Section III. Hardware Implementation is illustrated in Section IV. Some conclusions are given in Section V. 


\section{THREE PHASE SINE PWM BASED INVERTER FED INDUCTION MOTOR DRIVE}

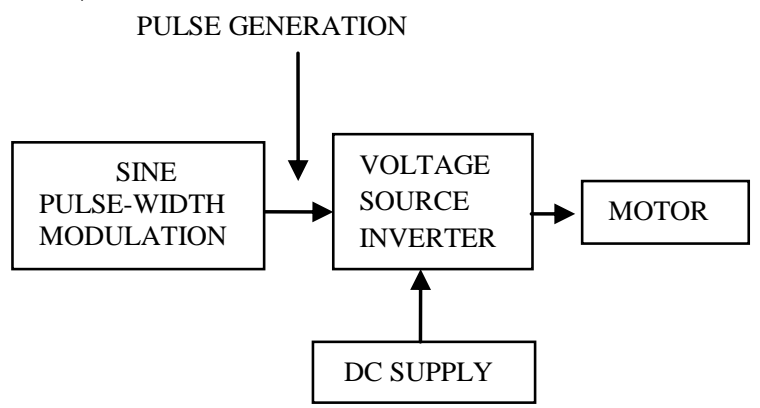

Fig.1.General Block diagram of proposed system.

Here, three phase shifted line frequency sinusoidal signal is compared with high frequency triangle carrier to produce sinusoidal pulse width modulation signals as gate drive pulses for voltage source inverter. The input dc may be a constant source from the rectifier or it can also be used from solar photo voltaic array based system. The output of three phase voltage source inverter is fed to inductive load i.e. induction motor. The idea here is to control the speed of the three phase ac motor by changing the amplitude of sinusoidal voltage using gate drive signals. The output is controlled by the switching sequence of the inverter switches. In sinusoidal pulse width modulation the pulse width of a high frequency switching signal (carrier signal) is varied with respect to the amplitude of the low frequency signal. For sinusoidal pulse width modulation,

frequency of carrier wave, $V_{\text {Carrier }}=f_{s}$

frequency of $\sin$ wave, $V_{\text {control }}=f_{1}$

$$
\text { Where } \begin{aligned}
f_{s} & =P W M \text { frequency } \\
f_{1} & =\text { fundamental frequency }
\end{aligned}
$$

Inverter output voltage,

When,

$$
\begin{aligned}
& V_{\text {control }}>V_{\text {carrier }}, V_{R 0}=\frac{V_{d c}}{2} \\
& V_{\text {control }}<V_{\text {carrier }}, V_{R 0}=\frac{-V_{d c}}{2}
\end{aligned}
$$

\section{Where}

$$
\begin{aligned}
& V_{R Y}=V_{R 0}-V_{Y 0} \\
& V_{Y B}=V_{Y 0}-V_{B 0} \\
& V_{B R}=V_{B 0}-V_{R 0}
\end{aligned}
$$

In sinusoidal pulse width modulation based three phase voltage source inverter fed induction motor the speed can be controlled by controlling the inverter output by varying modulation index of SPWM presented in [5]. Induction motor speed control algorithm implemented using microcontroller [6]. FFT analysis and comparisons of SPWM ,SVPWM ,Third harmonic pulse width modulation for inverter fed induction motor presented in [6,7].The steady state characteristics of PWM based inverter fed induction motor presented in [13] shows the superior performance of the system over sinusoidal supply.

\section{SYSTEM DESIGN AND SIMULATION}

In this section, software implementation of three phase, 4 leg IGBT based inverter using PSpice is presented. Conceptual circuit diagram of software implementation for voltage source inverter shown in Fig.2.Switching pulses generated using sine PWM approach and used to trigger the three phase inverter

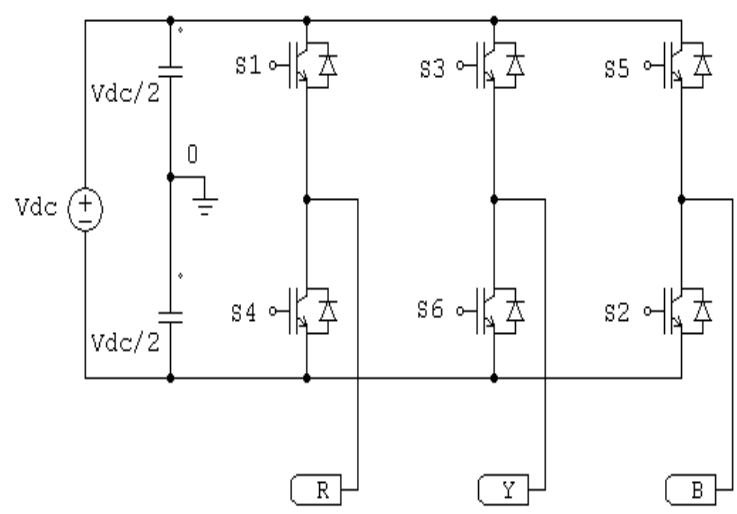

Fig.2. Conceptual circuit diagram

High frequency switching pulses generated using three sinusoidal signals each shifted by 120 degree phase compared with high frequency triangular carrier waves.
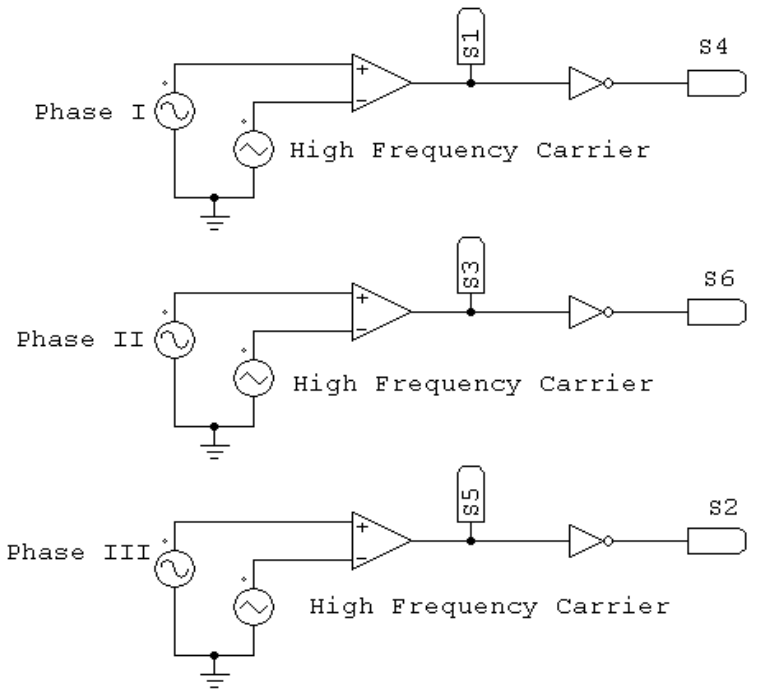

Fig.3. Gate drive signals for three phase VSI

Three high frequency drive signals generated using software approach to trigger S1, S3, S5 and inverted signals of above drive signals applied to trigger S4, S6 and S2 IGBT of the of the three phase inverter shown in Fig.4. 


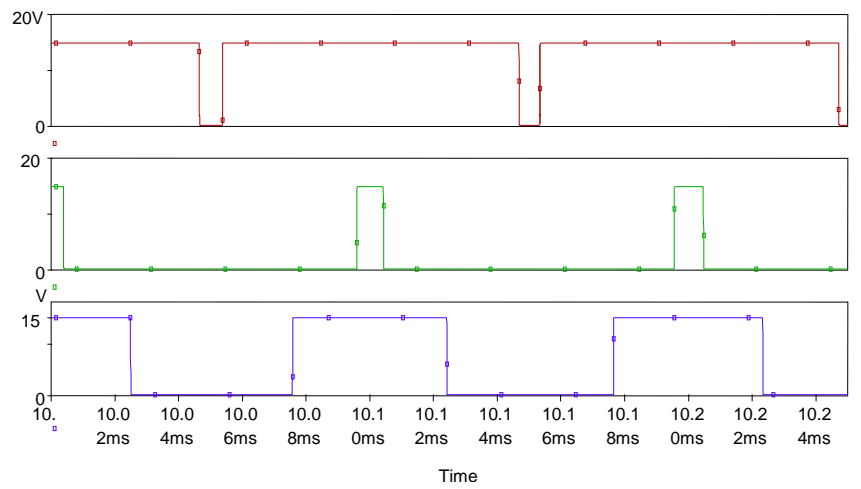

Fig.4. Drive signals for three phase voltage source inverter

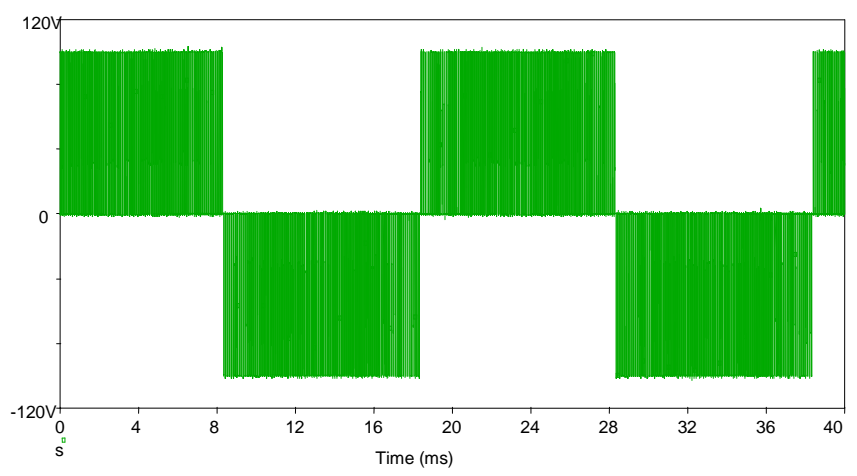

Fig.5. Output voltage of inverter between R-Y phase.

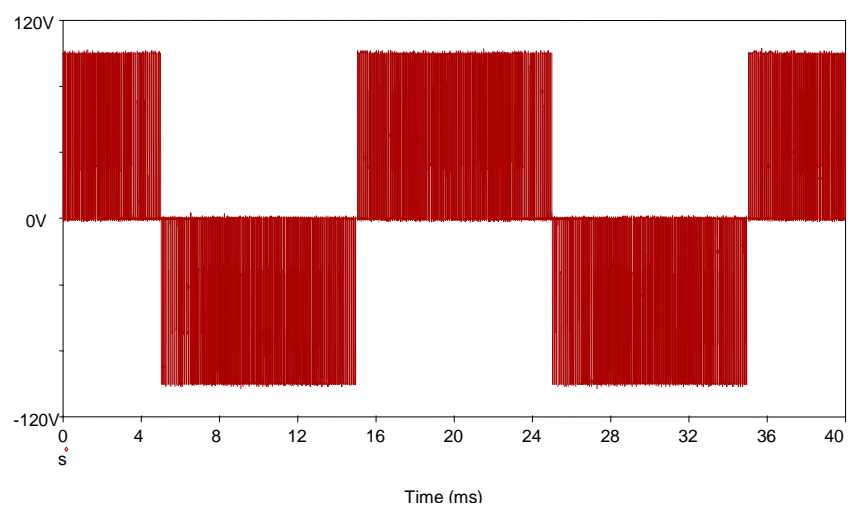

Fig.6.Output voltage of inverter for Y-B phase.

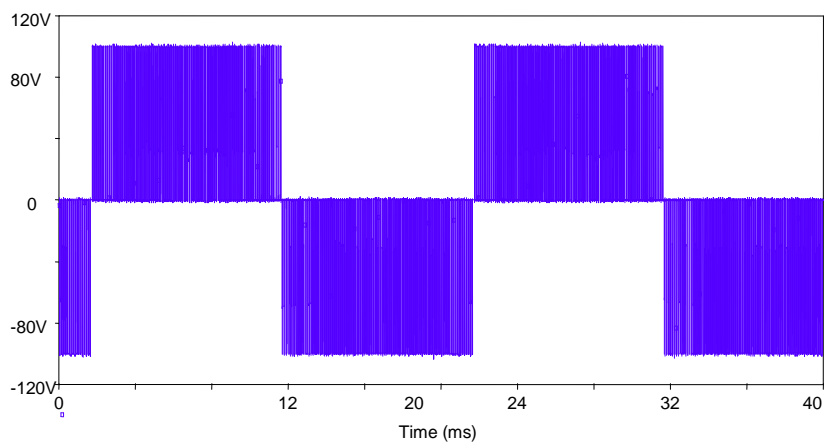

Fig.7.Output voltage of inverter for R-B phase.

The output voltages of three phase voltage source inverter between different phases are shown in Fig.5 to7.

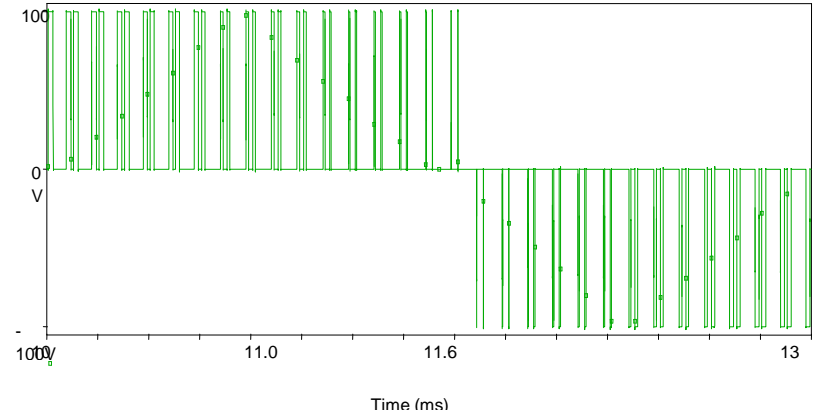

Fig.8.Insight view for output voltage of R-phase.

\section{HARDWARE IMPLEMENTATION}

In this section, real time hardware implementation is discussed. General block diagram of PWM switching pulse generation using Digital Signal processor for Induction motor is as shown in Fig.9

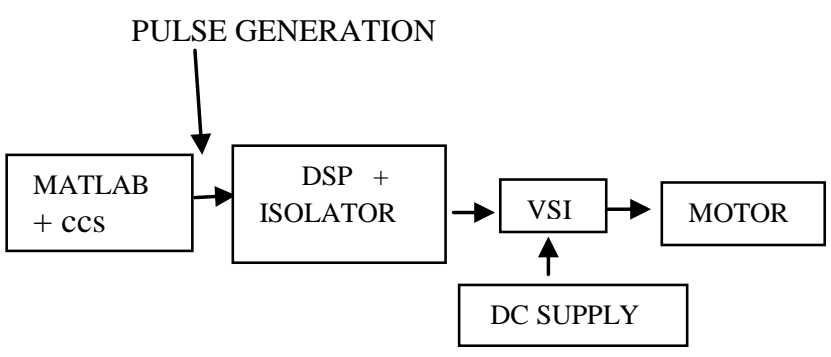

Fig.9.Block diagram of Pulse Generation using DSP

SIMULINK-MATLAB model has been developed based on sinusoidal pulse width modulation technique [12]. DSP code has been generated using MATLAB Simulink and Code Composer Studio. DSP code has been downloaded in DSP module and six drive signals were generated. Drive signals given to voltage source inverter through isolator board. DC supply and drive signals given to the inverter.

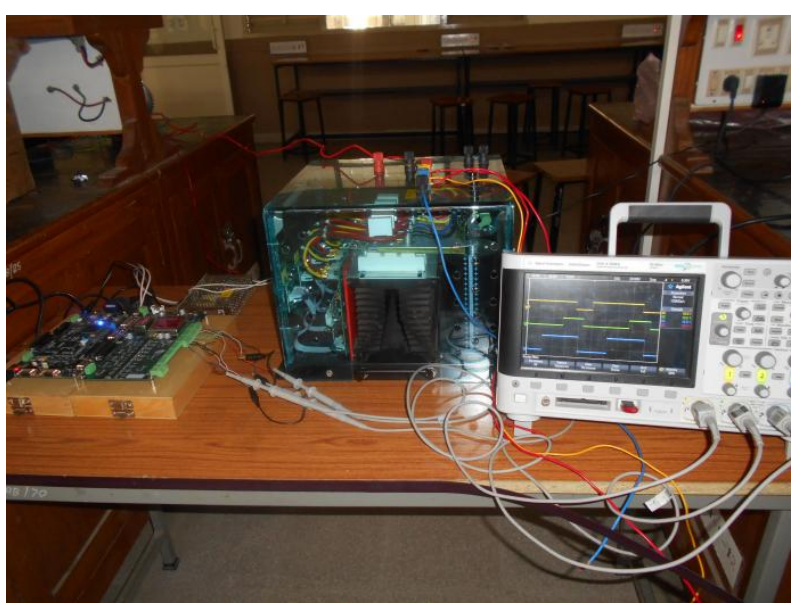

Fig.10. MATLAB Simulink based SPWM generation

Three phase controlled inverter output voltage generated by inverter applied to the three phase induction motor. Sine pulse width modulation technique is implemented using matlab simulink real time workshop tool box. Sine wave source,data type conversion, Pulse width modulation (PWM) blocks selected from DSP system toolbox. Real time code generated using following MATLAB -simulink model and code composer studio(V3.3). Simulink model parameters 
configured for real time code generation.This generated code is downloaded to TMS 320F28335 Module.PWM isolator module connected to DSP module. Six high frequency drive signals given to three phase voltage source inverter. Six drive signals were generated using ePWM module. ePWM module consist of two sections as ePWMA and ePWMB. Invert signal of ePWMA generated by ePWMB. Three high frequency drive signals of ePWMA captured using high resolution 4 channel DSO and shown in Fig.11. High frequency drive signals with different time span as shown in Fig.12.The magnitude of the drive signal was 17.3 Volt with $9.99 \mathrm{kHz}$ frequency for all the three drive signals.

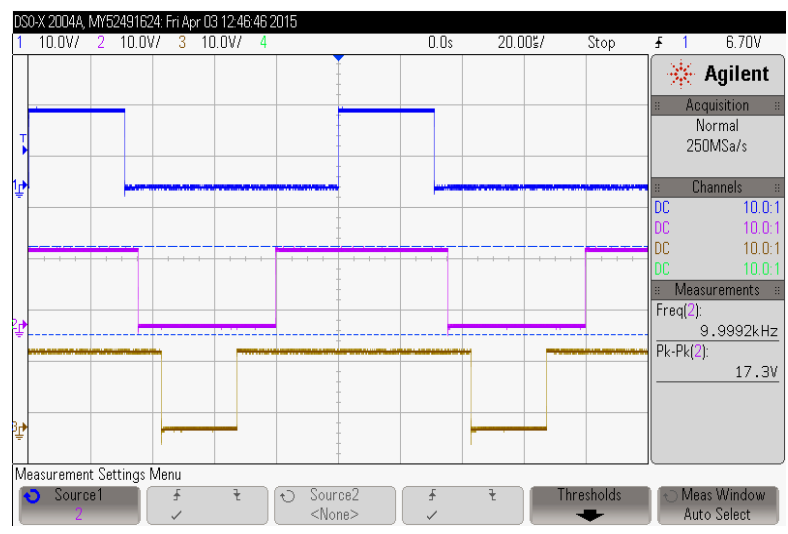

Fig.11. Drive signals for three phase voltage source inverter.

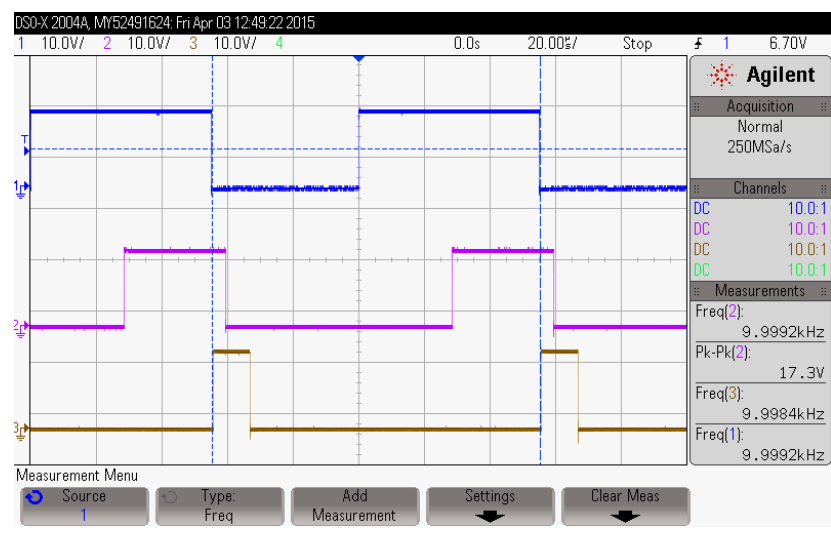

Fig.12. High frequency drive signals.

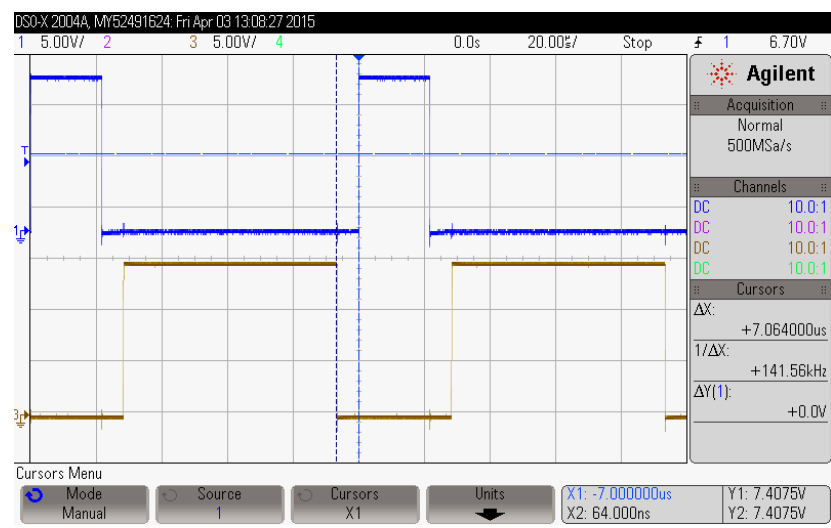

Fig.13. Dead band between normal $\&$ inverted drive signal.

Dead band is obtained by configuring parameters of pulse width modulation (PWM) block. As per the specification of the inverter stack, dead band is calculated and parameters configured in PWM block to obtain desired dead band between normal \& inverted drive signal. Dead band was programmed for 7 micro second for the implementation and captured using DSO as shown in Fig.13. Six high frequency drive signals were applied to Three phase,4-leg IGBT based Inverter. Inverter output voltage without filter captured using DSO as shown in Fig.14. The magnitude of the output voltage was 99 volt and $50 \mathrm{~Hz}$ frequency. The more insight view of the output voltage is shown in Fig.15.

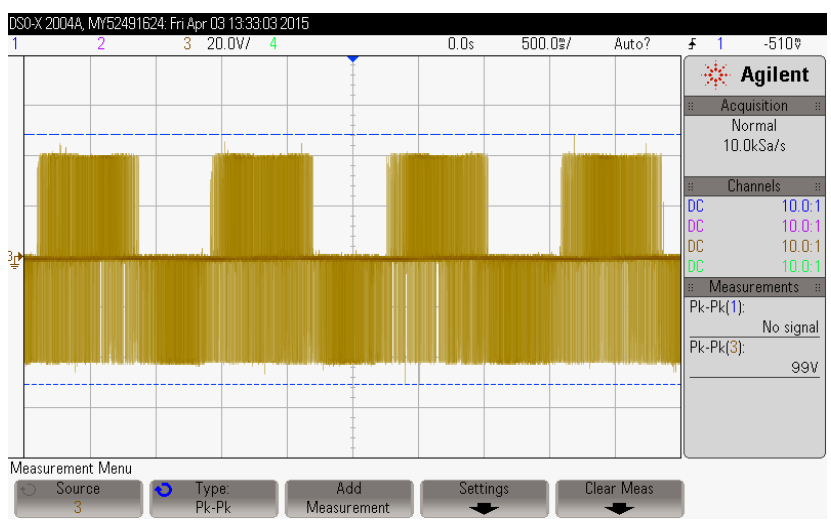

Fig.14 . Output voltage of inverter.

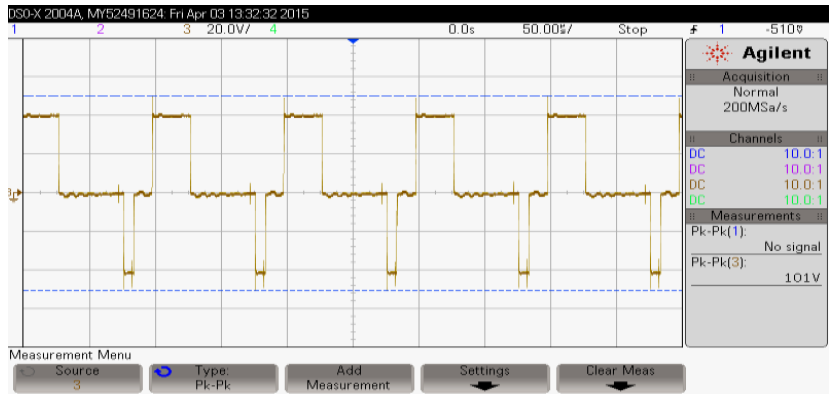

Fig.15. Insight view of output voltage.

Table 1. Output voltage for $85 \%$ peak duty cycle

\begin{tabular}{|c|c|c|}
\hline & Software & Hardware \\
\hline $\mathbf{V}_{\text {dc }}($ volt $)$ & $\begin{array}{c}\mathbf{V}_{\text {p-p }} \\
\text { (Volt) }\end{array}$ & $\mathbf{V}_{\mathbf{p} \text {-p }}$ (Volt) \\
\hline 50 & 100 & 97 \\
\hline 52 & 105 & 101 \\
\hline 55 & 110 & 106 \\
\hline 60 & 120 & 113 \\
\hline 65 & 130 & 126 \\
\hline 70 & 140 & 135 \\
\hline 75 & 150 & 146 \\
\hline 80 & 160 & 153 \\
\hline 90 & 180 & 173 \\
\hline 100 & 200 & 192 \\
\hline
\end{tabular}


Table 2. Inverter stack Specifications

\begin{tabular}{|l|l|}
\hline Switching frequency & $10 \mathrm{kHz}$ \\
\hline Input DC voltage & $600 \mathrm{~V}$ \\
\hline Output AC voltage & $415 \mathrm{~V}$ \\
\hline Output AC current & $10 \mathrm{~A}$ \\
\hline Output Frequency & $50 \mathrm{hz}$ \\
\hline
\end{tabular}

High frequency voltage source inverter specifications are mentioned in Table.2.Switching frequency is clearly shown in results (Fig.11 \& 12). The three phase inverter module on which experiment performed is shown in Fig.10.Comparission of output voltages at different dc input are mentioned in Table.1.When the dc input voltage is 52 volts, the measured output 101V can be verified from Fig. 15.

\section{CONCLUSION}

This paper proposes sinusoidal pulse width modulation based gate drive signal generation for voltage source inverter fed induction motor drive. The high frequency gate drive signals were generated through highly efficient DSP controller with isolator. Dead band was precisely programmed for three phase operation. Extensive simulation was carried out using orcad capture PSpice and the hardware implementation was verified with utilization of real time workshop module of MATLABSimulink and Code Composer Studio. The prototype was carried out for $100 \mathrm{~V}$ ac output because of the limitation of isolation for three phase system. This system can be integrated with renewable energy sources for various applications like water pumping, dc to three phase ac inverter, motor control.

\section{ACKNOWLEDGMENTS}

The authors thank Power Electronics Laboratory of Electrical Engineering Department and Embedded system \&Research Laboratory of Electronics \& communication department of A.D.Patel Institute of Technology, New V.V.Nagar, Gujarat, India for their support.

\section{REFERENCES}

[1] B.K.Bose, "Modern Power Electronics and AC drives," Prentics Hall, 2002.

[2] R.Krishnan, "Electric Motor drives-Modeling,Analysis and control," Prentics Hall, 2001.

[3] M.H. Rashid, "Power electronics Handbook,"Pearson Education,2002

[4] L.Umanand, "Power Electronics" Wiley India Ltd ,2010.

[5] Neha Thakur, Rakesh Singh Lodhi,“ Computer Simulation of SPWM-VSI for Minimizing the starting torque and current in Asynchronous Motor," International Journal of Research (IJR) Vol-1, Issue-5, June 2014 ISSN 2348-6848 ,pp. 292-298.
[6] Prabaharan.V, Umamaheswaran.R, "Microcontroller based Speed Control of Sinusoidal PWM Inverter fed Three Phase Induction Motor," International Journal of Innovative Technology and Research, Volume No. 1, Issue No. 1, December-January 2013, pp.061-065.

[7] Nisha G.K., Z.V. Lakaparampil, S. Ushakumari, "FFT Analysis for Field Oriented Control of SPWM and SVPWM Inverter fed Induction Machine With and Without Sensor," International Journal of Advanced Electrical and Electronics Engineering, (IJAEEE), ISSN (Print) : 2278-8948, Volume-2, Issue-4, 2013,pp.151160.

[8] Gaber El-Saady, El-Nobi A. Ibrahim, Mohamed El besealy "V/F control of Three Phase Induction Motor Drive with Different PWM Techniques," Innovative Systems Design and Engineering, ISSN 22221727(paper),ISSN 2222-2871 (ONLINE), Vol.4, No.14, 2013,pp 131-144

[9] M.Veerachary, Agnivesh Gupta,“ Digital simulation of sinusoidal PWM Inverter fed Induction motor," IEEE 1999 International Conference on Power Electronics and Drive Systems, PEDS'99, July 1999, Hong Kong.,pp.411-415.

[10] S. A. Saleh, M. A. Rahman,“ Experimental Testing of a Novel Control for Inverter-Fed Three-Phase Induction Motor,"1708972, Power Engineering Society General Meeting, 2006. IEEE

[11] Holmes, D. G. and Lipo, T. A., "Pulse width modulation for power converters: principles and practice," IEEE Press, 2003, pp. 230

[12] F. R. Lara, F.J. Jiménez, V. Barranco, "SPWM on DSP. frequency control in feed signal to study the acoustic noise in electrical motors," XIX International Conference on Electrical Machines - ICEM 2010, Rome.

[13] P.S.Chaudhari, Dr.P.M.Patil, S.S.Patil, P.P.Kulkarni, R.M.Holmukhe, "Comparison of Performance Characteristic of Squirrel Cage Induction Motor by Three Phase Sinusoidal and PWM Inverter Supply using MATLAB Digital Simulation," IEEE Third International Conference on Emerging Trends in Engineering and Technology,2010,pp.362-367.

[14] Upama Bose, K. Divya, Vallathur Jyothi, Sreejith.S,' Performance Analysis of Four-switch Three-phase Inverter-fed Induction Motor drive," 2014 IEEE Power and Energy Systems: Towards Sustainable Energy.

[15] Student version-Pspice.

[16] www.mathworks.com/MATLAB2012B

[17] www.ti.com 